\title{
DEFICIÊNCIA COMO PRIVAÇÃO DE LIBERDADES: EM BUSCA DO DIREITO AO DESENVOLVIMENTO DA PESSOA COM DEFICIÊNCIA
}

Amanda Luna Torres Zenaide ${ }^{1}$

Hertha Urquiza Baracho ${ }^{2}$

RESUMO: O artigo visa resgatar o processo de construção da noção de desenvolvimento, a partir do seu tradicional enfoque na concepção de crescimento econômico, o qual, posteriormente, veio a se sediar na ideia proposta por Amartya Sen de melhoria de vida e ampliação das liberdades dos indivíduos, tem como objetivo destacar a necessidade de eliminação das barreiras, que impedem às pessoas com deficiência o acesso aos serviços e bens essenciais ao desenvolvimento humano, como forma de, assim, evitar que, privadas de suas capacidades e oportunidades, venham a ser atingidas pela "armadilha da pobreza", estigma fortemente presente neste grupo de vulneráveis.

Palavras-chave: Pessoa com Deficiência. Inclusão. Acessibilidade. Desenvolvimento Social. Igualdade de Direitos.

\section{DEFICIENCY AS A DEPRIVATION OF LIBERTIES: IN SEARCH OF THE RIGHT TO THE DEVELOPMENT OF THE DISABLED PERSON}

\begin{abstract}
The present article aims to rescue the process of constructing the notion of development, part of its traditional focus on the conception of economic growth. This project, based on Amartya Sen's life and growth ideas, aims to highlight the need to eliminate barriers that prevent people with disabilities from accessing services and goods essential to human development. Thus, it is necessary to revisit these questions, in order to avoid them being hit by the "poverty trap", deprived of their capacities and opportunities.
\end{abstract}

Keywords: Disabled Person. Inclusion. Accessibility. Social development. Equal rights.

\footnotetext{
${ }^{1}$ Graduada em Ciências Jurídicas pelo Centro Universitário de João Pessoa. Especialista em Direito Público pela Universidade Anhanguera - UNIDERP . Mestranda em Direito e Desenvolvimento Sociopolítico Sustentável no Centro Universitário de João Pessoa. Advogada sócia do escritório Mouzalas, Borba \& Azevedo Advogados Associados.

${ }^{2}$ Possui Graduação em Ciências Jurídicas pela Universidade Federal da Paraíba (1980), Mestrado em Direito do Estado (Direito Constitucional) pela Pontifícia Universidade Católica de São Paulo (1984), Doutorado em Direito do Estado (Direito Constitucional) pela Pontifícia Universidade Católica de São Paulo (1993) e Pós-Doutorado na Università degli Studi di Firenze, UNIFI, na área de Ciencias Sociais Aplicadas. Professor Associado III da Universidade Federal da Paraíba (aposentado), foi Chefe do Departamento de Direito Público.(UFPB). Atualmente é Professora Titular de Direito Econômico no Centro Universitário de João Pessoa- UNIPÊ e Professora Colaboradora da UFPB, atuando principalmente nos seguintes temas: constituição, desenvolvimento, propriedade e meio ambiente.
} 


\section{INTRODUÇÃO}

O direito ao desenvolvimento, a partir das mais variadas perspectivas, apresentou inúmeras concepções ao longo da história. Entretanto, por grande lapso de tempo, a sua noção restou filiada e focada ao aspecto econômico, isto é, à ideia de incremento na economia.

Até os anos 60, tinha-se o entendimento de que as poucas nações que se apresentavam desenvolvidas usufruíam desta condição em razão de ter auferido e acumulado riquezas por meio do processo de industrialização e, por outro lado, aqueles países que se encontravam pobres, assim estavam devido a ausência de possibilidades de se industrializar.

Destarte, por anos, não se enxergou a necessidade de se fazer qualquer distinção entre desenvolvimento e crescimento econômico. Contudo, gradativamente, os teóricos abandonaram a perspectiva de desenvolvimento com perspectivas voltadas ao viés monetário, para dar espaço a um enfoque multidimensional, com a finalidade de compreendê-lo em suas diversas dimensões, sejam elas: social, cultural, política etc.

Sem negligenciar acerca da pobreza e desigualdade passou-se a justificar o desenvolvimento para além de um conceito econômico, ou seja, um desenvolvimento global, balizado no respeito e na dignidade humana, com fins na melhoria da condição de vida dos indivíduos, notadamente dos pobres e vulneráveis, por serem mais carentes de bens e serviços essenciais ao mínimo existencial.

Neste contexto de desenvolvimento centralizado no bem-estar social, destaca-se a teoria proposta por Amartya Sen, a qual vem enfatizar que a razão primordial para falta de progresso de uma nação está sediada na pobreza, violação das liberdades políticas, fome, que ainda insistem em recair sobre a sociedade, sobretudo sobre aqueles que apresentam mais vulnerabilidade, a exemplo das pessoas com deficiência.

Assim, tendo-se como alvo o desenvolvimento das pessoas com deficiência e consoante a Teoria Seniana, o presente estudo objetiva analisar a importância de ser oportunizado às pessoas com deficiência, com baliza na igualdade material, o pleno gozo de todos os Direitos Humanos e liberdades fundamentais, como forma de impedir que venham a se tornar fáceis presas da armadilha da pobreza. ${ }^{3}$

Para tanto, por meio dos dados empíricos colhidos, os quais apontam que a maioria das pessoas com deficiência apresentam maiores taxas de desemprego e menor formação

\footnotetext{
3 Expressão utilizada por Ignacy Sachs (2001) na obra Desenvolvimento Includente, Sustentável, Sustentado.
} 


\section{DEFICIÊNCIA COMO PRIVAÇÃO DE LIBERDADES: EM BUSCA DO DIREITO AO DESENVOLVIMENTO DA PESSOA COM DEFICIÊNCIA}

educacional do que aquelas que não possuem deficiência, e de uma análise quantitativa e qualitativa da pesquisa documental e bibliográfica, buscar-se-á, igualmente, demonstrar a relação de causa e efeito da pobreza para com a deficiência, destacando-se a imprescindibilidade da identificação/remoção das barreiras que privam das liberdades as pessoas com deficiência, bem assim da promoção de mudanças culturais, legislativas, políticas, institucionais e ambientais, necessárias ao desenvolvimento destes indivíduos.

\section{DIREITO AO DESENVOLVIMENTO}

A concepção de desenvolvimento voltada à acumulação de riquezas, industrialização e tecnologia foi concebida na modernidade, mediante a Teoria do Liberalismo Clássico de Adam Smith (1996). Com o tempo esta concepção tornou-se constrita à percepção de crescimento econômico, foi utilizada como expressão sinônima de progresso e bem-estar social.

Consoante às teorias propostas por David Ricardo e Karl Marx, o desenvolvimento de um país no século XIX passou a ser evidenciado pelo acúmulo do excedente de capital. Para David Ricardo (1996), o processo de desenvolvimento estaria calcado na cumulação de riquezas, todavia, para que não houvesse desequilíbrios e diminuição do excedente, deveria o Estado não se imiscuir no Mercado.

Sem discordar de Ricardo, no sentido de que o desenvolvimento teria origem no acúmulo de capital, Karl Marx (1946) diverge deste pensamento ao dizer que é intrínseco ao desenvolvimento o aumento de desigualdades, na medida em que o progresso social, no capitalismo, gera antagonismo. De um lado, maior quantidade de riquezas à disposição do capital e, de outro, uma destacada miséria da classe operária.

A reforçar a noção de desenvolvimento como crescimento econômico, no século seguinte, destaca-se a teoria do economista Simon Kuznets (1955), conhecida como "U" invertido. Para ele, o crescimento econômico, de início, implicaria o aumento do desequilíbrio entre países pobres e ricos, mas que posteriormente mediante a industrialização e urbanização dos países em desenvolvimento, tal desigualdade seria desacentuada.

Com efeito, até os anos 60, tinha-se a ideia de que as poucas nações que se encontravam desenvolvidas tinham se tornado ricas em decorrência da industrialização e que os países pobres seriam aqueles que haviam permanecido no subdesenvolvimento, por não terem experimentado um considerável processo de industrialização. Exatamente por isso, não existia a necessidade de se fazer qualquer distinção entre desenvolvimento e crescimento econômico. (VEIGA, 2006). 
Destarte, após a década de 60, os teóricos abandonaram, gradativamente, a perspectiva de desenvolvimento com tangências voltadas puramente ao aspecto econômico, para, com um enfoque multidimensional, compreendê-lo em suas diversas dimensões. Observou-se que, ao justificar o desenvolvimento a partir de premissas monetárias, as teorias estariam a negligenciar a pobreza e a desigualdade. (COUTINHO, 2013).

Viu-se que, entender de modo diverso, isto é, pelo desenvolvimento limitado ao aumento de renda de um país ou ao seu PIB, seria o mesmo que promover um crescimento pela ausência de igualdade, o qual viria a engendrar uma involução com potencial de produzir efeitos sociais perversos, a exemplo da pobreza e deterioração das condições de vida dos menos favorecidos. (SACHS, 2001).

Assim, o progresso que vem a priorizar os aspectos econômico, social e cultural, com vistas à melhoria das condições de vida humana, apresenta-se, de fato, como o verdadeiro desenvolvimento, cuja base se mostra firmada na transversalidade e no modelo plural de reestabelecimento de capacidades e de evolução da população. (FURTADO, 1968).

Neste contexto, o indivíduo veio a ter um papel de importante destaque na construção do conceito de desenvolvimento, mormente porque passou a ser visto como sujeito central e fundamental destinatário deste processo, de modo que as condições de vida se afiguram, então, determinantes para o grau de progresso de uma sociedade. (SANTOS, 2011).

Estudos mostram que o termo "direito ao desenvolvimento" foi inicialmente utilizado, em 1972, pelo ministro da primeira corte do Senegal - Keba Mbaye, na aula inaugural do Instituto Internacional de Direitos Humanos. Entrementes, foi com a Resolução de no 41/128 da Assembleia Geral das Nações Unidas, ocorrida em 1986, que houve a originária manifestação jurídica normativa acerca do direito humano ao desenvolvimento.

Foi ali que ficou estabelecida a Declaração do Direito ao Desenvolvimento, onde, em seu art. $1^{\circ}$, restou definido como sendo um direito humano inalienável, segundo o qual toda pessoa ou todos os povos estão habilitados a participar do desenvolvimento econômico, social, cultural e político, de modo que todos os Direitos Humanos e liberdades fundamentais possam ser realizados, em sua plenitude.

Neste viés, ressalta-se o desenvolvimento como um processo não linear e unilateral, que, incorporado ao crescimento econômico, enseja a diminuição das desigualdades e concentração de renda, a partir de uma melhoria dos indicadores sociais de educação, saúde, trabalho, com vistas à efetivação dos Direitos Humanos. (SENGUPTA, 2005). 


\section{DEFICIÊNCIA COMO PRIVAÇÃO DE LIBERDADES: EM BUSCA DO DIREITO AO DESENVOLVIMENTO DA PESSOA COM DEFICIÊNCIA}

Dentro da perspectiva de que o real crescimento de uma nação ultrapassa o aspecto monetário, de maneira a se fundar na evolução social, isto é, no processo de desenvolvimento das capacidades humanas, do bem-estar da sociedade - sem qualquer exclusão, sobressai-se a teoria do economista indiano Amartya Sen.

\section{DESENVOLVIMENTO NA PERSPECTIVA DE AMARTYA SEN}

Para Sen (2010), a concepção mais adequada de desenvolvimento seria aquela que, sem se descurar da relevância do crescimento econômico, o associa a uma qualidade de vida humana melhor, a partir da ampliação das liberdades substantivas, quais sejam, educação, saúde, alimentação etc. Segundo seus ensinamentos:

A ligação entre liberdade individual e realização de desenvolvimento social
vai muito além da relação constitutiva - por mais importante que ela seja. O
que as pessoas conseguem positivamente realizar é influenciado por
oportunidades econômicas, liberdades políticas, poderes sociais e por
condições habilitadoras, como boa saúde, educação básica e incentivo e
aperfeiçoamento de iniciativas. As disposições institucionais que
proporcionam essas oportunidades são ainda influenciadas pelo exercício das
liberdades das pessoas, mediante a liberdade para participar da escolha social
e da tomada de decisões públicas que impelem o progresso dessas
oportunidades. (SEN, 2010, p. 19).

Desta forma, a ideia de desenvolvimento ultrapassa a acumulação de riqueza ou variáveis atreladas à renda, para se sedimentar em um desenvolvimento vinculado às oportunidades e condições que propiciem o exercício e a expansão das liberdades, bem como favoreçam a eliminação de privações suportadas pelos indivíduos, como a pobreza, falta de oportunidades econômicas, intolerância, exclusão social, negligência de serviços públicos.

Com efeito, o óbice às liberdades termina por acarretar, segundo a Teoria Seniana, o tolhimento de outras tantas capacidades, que, por conseguinte, vêm a originar privações de outras várias liberdades, em um nítido processo retroalimentar, razão pela qual o desenvolvimento humano implica, pois, a remoção das barreiras que limitam as escolhas e oportunidades dos indivíduos.

Disto se extrai que a ampliação da liberdade, que é a potência de o indivíduo alcançar o bem-estar que racionalmente almeja é avaliada como finalidade e a principal condição do desenvolvimento, a possuir um papel constitutivo e, ao mesmo tempo, instrumental, na medida em que, no momento em que assegura direitos, igualmente, faz surgir outros. (SEN, 2010).

Quanto maior a liberdade dos indivíduos, maior será a chance de se tornarem melhores e, deste modo, interferir de forma positiva na comunidade em que vivem. Neste contexto, a 
privação de uma liberdade individual, que certamente influenciará toda uma cadeia de liberdades e direitos individuais, não é somente prejudicial para o indivíduo, mas sim a toda sociedade.

Desta forma, o desenvolvimento de uma nação depende não só da faceta econômica, consoante as abordagens teóricas tradicionais, como também de um processo em que os indivíduos, como agentes, expandem suas capacidades pessoais para decidirem, com liberdade, fazer aquilo que valorizam e que os deixa felizes e a exercer, assim, uma verdadeira cidadania.

Neste trilhar, quando se tem em mira as pessoas com deficiência, não é outra a conclusão senão a de que a elas o direito ao desenvolvimento é obstado, na medida em que são, diuturnamente, privadas de ser agentes sociais, porquanto tal condição é propiciada pelas oportunidades econômicas, sociais, políticas e culturais disponíveis ao indivíduo, as quais lhes são negadas.

Baseado na concepção seniana, Veiga (2006) ensina que há quatro capacidades humanas que são tidas como elementares, sendo elas: ter uma vida longa e saudável; ser instruído; ter acesso aos recursos necessários a um nível de vida digna e ser capaz de participar da vida em comunidade. Não há dúvida de que, ao se tratar de pessoas com deficiência, todas estas capacidades se mostram afastadas.

Deste modo, faz-se mister voltar uma maior atenção a este grupo de vulneráveis, com vistas à expansão das suas liberdades, a fim de possibilitar, pois, que as pessoas com deficiência venham a agir livremente, isto é, sem ser privados pela pobreza, ante a ausência de oportunidades, exclusão social e negação de direitos políticos e civis.

\section{DEFICIÊNCIA COMO PRIVAÇÃO DE POTENCIALIDADES}

As liberdades individuais possuem aspectos relevantes, dentre os quais se destacam dois: oportunidade e processo, muito bem ilustrados por Sen (2010). No que tangencia à oportunidade, esta se refere à existência de alternativas para o alcance das escolhas pessoais, já no que diz respeito ao processo, este corresponde ao contexto que leva o indivíduo poder fazer a sua opção.

Na hipótese de uma pessoa com deficiência não conseguir, por exemplo, alfabetizar-se, ela poderá ser privada do direito à empregabilidade (ausência de oportunidade), em decorrência, certamente, da inexistência de políticas públicas voltadas à educação (processo impróprio), e ratificar-se, assim, o estigma da pobreza incidente, expressivamente, sobre as pessoas com deficiência.

Revista Brasileira de Direitos e Garantias Fundamentais | e-ISSN: 2526-0111 | Salvador | v. 4 | n. 1 | p. 131 - 147 | Jan/Jun. 


\section{DEFICIÊNCIA COMO PRIVAÇÃO DE LIBERDADES: EM BUSCA DO DIREITO AO DESENVOLVIMENTO DA PESSOA COM DEFICIÊNCIA}

Neste diapasão, tem-se que, no caso das pessoas com deficiência, as fontes de privação das liberdades tanto são oriundas da restrição/ausência de oportunidades, como, também, derivam dos inadequados processos. Entretanto, este cenário não é atual, portanto, há muito, as pessoas com deficiência são privados de autonomia e de toda sorte de direitos, restando apenas se resignar em serem destinatários de práticas assistencialistas.

A despeito de não estarmos vivendo sob a égide do modelo reabilitador ou médico, que difundia a ideia de deficiência com base nas limitações funcionais individuais, mas sim sob o amparo do modelo social, que preconiza a percepção de deficiência fundada nas barreiras arquitetônicas, programáticas, metodológicas, instrumentais, comunicacionais e atitudinais, não restam dúvidas de que a sociedade ainda precisa ser reabilitada. (DINIZ, 2003).

É notório que as referidas limitações funcionais dos indivíduos ainda permanecem sendo raízes deste complexo fenômeno, conquanto se mostre inegável que é no seio da sociedade que se encontram os maiores óbices para que as pessoas com deficiência possam ser levadas em consideração na organização social, a partir da promoção da igualdade de oportunidades.

Com efeito, o Estado brasileiro, no art. $1^{\circ}$, II e III, da CF/88, elegeu como fundamentos da República a cidadania e a dignidade da pessoa humana, a erigir como seus objetivos fundamentais, no art. 3o, I, III, IV, a construção de uma sociedade livre, justa e solidária; a erradicação da pobreza e redução das desigualdades sociais, bem assim a promoção do bem de todos, sem preconceitos e quaisquer formas de discriminação.

Outrossim, ratifica a Lei Maior, como sendo a igualdade um princípio fundamental, ao afirmar, no art. 5o, que “todos são iguais perante a lei, sem distinção de qualquer natureza”. E é exatamente neste princípio que está radicada a ideia de inclusão, traduzida na garantia de condições e oportunidades a todas as pessoas, com o devido respeito às suas particularidades.

Ocorre que, por ter o processo de exclusão das pessoas com deficiência, há muito sedimentando, engendrado uma concepção de deficiência atrelada a ideia de inutilidade, invalidez, ineficiência e dependência, a ampla legislação existente (nacional ou internacional) ainda não se mostra suficiente a concretizar os direitos mais essenciais a este grupo de vulneráveis, sendo até mesmo necessário um forte investimento, no que concerne às políticas públicas inclusivas, para que, assim, deixe a igualdade material de ser apenas um fim almejado.

Balizada num contexto de construção e opressão de ordem social, a Convenção da ONU sobre os Direitos da Pessoa com Deficiência - CDPD vem se mostrar como uma ferramenta de capital relevância para a transformação da sociedade, quando determina a inclusão da pessoa 
com deficiência em todas as instâncias de participação, a promover o pleno e equânime exercício de todos os direitos e liberdades fundamentais.

Vê-se, desta forma, que as pessoas com deficiência, ao contrário da visão de desenvolvimento proposta por Amartya Sen, estão longe de ter acesso a valores que sustentam os Direitos Humanos, porquanto, sem liberdade, ainda há um longo caminho a ser percorrido por elas, para o alcance de oportunidades econômicas, liberdades políticas, poderes sociais e condições habilitadoras.

Inclusive do ponto vista da autonomia, a privação às pessoas com deficiência é fato incontroverso, quando se percebe que, rotineiramente, são impedidos de se autor regular, bem assim de direcionar suas vontades, objetivos e decisões sobre o seu próprio destino. (PALACIOS; BARIFFI, 2007).

E neste aspecto da ampliação das liberdades trazida por Sem que há uma grande coincidência com o que fundamenta o modelo social de eficiência, que é exatamente a garantia da liberdade como pressuposto para o desenvolvimento de capacidades, na medida em que promove a conquista de direitos fundamentais e oportunidades em iguais condições aos que não possuem traços peculiares.

Dentro do contexto de liberdade e autonomia das pessoas com deficiência, um enfoque importante a ser dado é acerca do direito que têm elas de viverem em comunidade, sem preconceitos, de forma visível, sem que, portanto, fiquem escondidas em hospitais, como nos tempos em que a deficiência era institucionalizada, ou, até mesmo, ocultadas em suas próprias residências.

Não há razões mais para tentar apagar ou tornar invisível a deficiência, sob pena de se perpetuar a condição de não cidadãos em que viverem, porquanto a marginalização e exclusão das pessoas com deficiência devem ficar na antiguidade clássica e idade média, período este em que o Estado permitia, inclusive, a prática da eugenia neste grupo de vulneráveis. (COULANGES, 2003).

Efetivamente, a ausência de visibilidade termina por causar a falta de participação das pessoas com deficiência na vida política, a partir das barreiras à informação; à votação ou ao acesso a cargos públicos, bem assim à vida social, a partir do momento em que se inibe o direito de acesso à cultura, lazer, esporte.

Destaque-se, outrossim, que esta circunstância de desigualdade e segregação, a qual remete ao conceito de cidadania, que pautada na liberdade e democracia é uma categoria 


\section{DEFICIÊNCIA COMO PRIVAÇÃO DE LIBERDADES: EM BUSCA DO DIREITO AO \\ DESENVOLVIMENTO DA PESSOA COM DEFICIÊNCIA}

político-jurídica de atribuição à pessoa humana de determinados direitos civis, políticos e sociais, assim como de deveres em face da comunidade à qual pertence (LAFER,1988), deve ser analisada como um importante fator do estigma da pobreza das pessoas com deficiência.

Deste modo, a abordagem trazida por Amartya Sen sobre as habilidades individuais, mostra-se bastante relevante e de grande utilidade para a compreensão do desenvolvimento das pessoas com deficiência, mormente porque, compatível com o modelo social de deficiência, volta-se a sua base teórica para os Direitos Humanos entre as pessoas com deficiência, a promover a noção de estes viverem em piores condições de vida e terem menos recursos materiais.

\section{DEFICIÊNCIA E O ESTIGMA DA POBREZA}

A pobreza é um fenômeno complexo que no decorrer dos últimos anos começou a ser visto como multifacetado. Diversos enfoques a ela são dados, a partir da correlação que se faz, sobretudo, com a ideia de bem-estar material, ou seja, de níveis de rendas auferidos, bem assim com a concepção de privação de capacidades e oportunidades.

Segundo o relatório dos anos 90 emitido pelo Banco Mundial, a definição de pobreza consistiria na incapacidade de atingir um padrão mínimo, isto é, na ausência de capacidade de consumir o básico, para que, com o alcance de um padrão mínimo de nutrição, saúde, educação etc, pudesse o indivíduo viver, minimamente, em boas condições. (BANCO MUNDIAL, 1990).

Como forma de combate e diminuição da pobreza, apontaram-se, no referido relatório, as necessidades de criação de políticas públicas que fomentassem a ampliação de oportunidades econômicas, de modo a possibilitar ao pobre o aumento do seu capital e estimular a promoção de prestação de serviços sociais voltados, nomeadamente, à educação e saúde.

Para Sen (2010), ao revés de se concentrar no fator exclusivamente monetário - critério clássico para identificação do referido fenômeno, a pobreza é percebida como privação de capacidades básicas. Neste viés, o autor não nega a ideia de que a pouca renda é uma das causas fundamentais da pobreza, porquanto pode ser uma razão básica da privação de capacidades de uma pessoa.

Com efeito, consoante o relatório de 2000-2001, lançado pelo Banco Mundial, a pobreza passou a ser concebida de forma distinta, sendo, inclusive, propostas novas maneiras para a sua erradicação. De um olhar voltado para a variável renda, passou-se, pois, a compreender a pobreza como um fenômeno engendrado por diversas privações decorrentes de processos econômicos, sociais e políticos. (UGÁ, 2004). 
A pobreza, deste modo, deixa de ser encarada por meio de um enfoque unilateral, na medida em que é identificada para além de uma abordagem aportada no baixo nível de renda, isto é, em sua forma monetária, sendo, portanto, considerada como causa de múltiplas privações de capacidade básicas de se alcançar os objetivos traçados pelos indivíduos.

Percebe-se, assim, que a Teoria Seniana teve influência relevante na construção do conceito de pobreza lançado pelo Banco Mundial, uma vez que, sem concentrar as suas balizas em uma limitada análise econômica, identifica-a como privação de capacidades, capaz de reduzir o potencial do indivíduo em auferir riquezas.

Sendo a liberdade, portanto, um fator de ampliação das potencialidades humanas, segundo Amartya Sem, há uma nítida correlação entre deficiência e pobreza. Privadas de alternativas para atingir aquilo que objetivaram para suas vidas, em razão de contexto/processo inadequado que não lhes permitem a possibilidade de fazer opções, as pessoas com deficiência podem se afigurar, facilmente, como pobres.

Com a carência de tantas liberdades, as pessoas com deficiência têm reduzida a probabilidade de auferir ou melhorar os seus rendimentos, e demonstrar que a ausência de capacidades gera pobreza. Ou seja, as pessoas que possuem algum tipo deficiência têm uma maior chance de ser atingidas pela armadilha da pobreza, em decorrência do cerceamento de oportunidades sociais e econômicas.

Incide, assim, um processo em que as privações de capacidade se autorreforçam. Um cidadão que vive em condições não favoráveis e, portanto, tem reduzida a sua capacidade de transformar sua renda em funcionamentos, pode ser presa de uma espécie de círculo vicioso da pobreza: baixa capacidade de transformação renda-funcionamentos $\rightarrow$ baixos funcionamentos $\rightarrow$ baixa renda $\rightarrow$ baixa capacidade de transformação renda-funcionamentos. (PINHEIRO, 2012).

Neste sentido, a deficiência é uma questão de desenvolvimento, ante a sua relação bidirecional com a pobreza: tanto é uma causa como uma consequência deste fenômeno, antes de tudo porque ao obstar que as pessoas com deficiência possam ter acesso a bens e serviços, notadamente aqueles relacionados à saúde, a pobreza deve ser considerada como uma variável importante para o risco do surgimento de uma deficiência. 


\section{DEFICIÊNCIA COMO PRIVAÇÃO DE LIBERDADES: EM BUSCA DO DIREITO AO DESENVOLVIMENTO DA PESSOA COM DEFICIÊNCIA}

Um estudo $^{4}$ realizado em 56 países em desenvolvimento demonstrou que aqueles mais atingidos pela pobreza apresentavam um quadro de saúde pior do que os mais ricos, isto porque a pobreza pode fazer surgir problemas de saúde associados à deficiência, inclusive por meio de baixo peso ao nascimento, desnutrição, falta de água potável ou saneamento adequado, condições inseguras de trabalho e de vida e lesões, podendo, igualmente, favorecer que um doente venha a se tornar deficiente. (OMS, 2012).

Consoante números disponibilizados pelo Relatório Mundial sobre a deficiência, mais de um bilhão de pessoas possuem algum tipo de deficiência, o que representa um percentual aproximado de $15 \%$ da população mundial, a demonstrar que as pessoas com deficiência são a maior minoria do mundo. Inclusive, conforme a Organização Mundial de Saúde (OMS), este número está a aumentar, em razão do crescimento demográfico, avanços da medicina e processo de envelhecimento.

Ainda, dispõe o Centro Regional de Informações das Nações Unidas que, segundo o Programa das Nações Unidas para o Desenvolvimento (PNUD), 80\% das pessoas com deficiência vivem nos países em desenvolvimento, com a estimativa, emitida pelo Banco Mundial, de que 20\% das pessoas mais pobres tenham uma deficiência e em geral são consideradas como as mais desfavorecidas pelos membros da sua própria comunidade.

Outrossim, destaca-se que, com base nas informações das Nações Unidas colhidas a partir dos dados apresentados pela Organização Mundial do Trabalho (OIT), cerca de 386 milhões de pessoas em idade de trabalhar possuem algum tipo de deficiência, atingindo, contudo, o desemprego o índice de 80\%, em alguns países.

E, no que tange ao quesito educação, a UNESCO noticia que, nos países em desenvolvimento, 90\% das crianças com deficiência não frequentam a escola, não excedendo a taxa de alfabetização mundial, relativa aos adultos com deficiência, o percentual de $3 \%$, de acordo com o PNUD.

Neste contexto, a condição de deficiência se conecta à pobreza, precipuamente em virtude da dificuldade de inserção da pessoa com deficiência no mercado de trabalho, seja pelas limitações existentes em relação à capacitação profissional - em face da ausência de políticas públicas efetivas na seara da educação inclusiva, seja pelo preconceito e entraves à contratação

\footnotetext{
${ }^{4}$ Este dado pode ser encontrado no Relatório mundial sobre a deficiência, mais precisamente na página 7. Disponível em:

<http://www.pessoacomdeficiencia.sp.gov.br/usr/share/documents/RELATORIO_MUNDIAL_COMPLETO.p>. A cesso em: 17 de Out 2017.
} 
de pessoas pessoa com deficiência, que se constatam por duas vias principais: os maiores custos da mão de obra e a restrição de ganhos advindos do trabalho. (FRANÇA, 2014).

Segundo Oliver (2010), o qual fincou seus estudos acerca das pessoas com deficiência, examinando de maneira acurada o liame existente entre deficiência e modo de produção capitalista, a emergência do capitalismo fez engendrar a limitação das atividades atribuídas às pessoas com deficiência.

Isto porque, na oportunidade em que o trabalho assalariado se tornou mais ligado à indústria de grande escala, por volta o século XVIII, na Inglaterra, as grandes demandas de trabalho exigiam muito dos que laboravam. Era necessária muita habilidade, para atender às exigências laborais, devido as pessoas com algum tipo de deficiência não conseguirem atingir as expectativas, e, consequentemente, serem excluídas da atividade mercantil.

Note-se que, desde muito tempo, a pessoa com deficiência e a pobreza se alimentam mutuamente, pois que, compreendida como uma limitação funcional a pobreza, aos direitos mais elementares das pessoas com deficiência, a exemplo da educação, contribuindo para a redução de oportunidades de emprego, e, por conseguinte, de renda - situação esta que, certamente, importa em mais problemas para superar as barreiras que obstam o exercício dos direitos fundamentais. (FERRAZ, 2014).

Não é ocioso lembrar que os próprios custos de vida da pessoa com deficiência, decorrentes das necessidades especiais em transporte, adaptação do lar, ferramentas de apoio, educação e, principalmente, saúde, podem chegar até três vezes os custos de uma pessoa sem deficiência, segundo estudo realizado em 15 países em desenvolvimento. (MITRA; POSARACK; VICK, 2011).

Nesse exato sentido, Amartya Sen, citado por Vital (2008), esclarece que as pessoas com deficiência têm gastos adicionais para satisfazer as mesmas necessidades daqueles que não possuem deficiência - o que denominou de deficiência por conversão, pelo que a linha da pobreza para as pessoas pessoa com deficiência deve levar em consideração esses gastos adicionais e imprescindíveis, para que vivam com dignidade.

Tais especialidades implicam diretamente a renda das pessoas com deficiência, que se veem suprimidas por duas grandes variáveis incidentes sobre a pobreza nesse grupo social: o acréscimo de gasto médio para o seu sustento e a dificuldade de obtenção de renda e inserção no mercado de trabalho. Essas variáveis, quando consideradas sobre o índice de pobreza dos 


\section{DEFICIÊNCIA COMO PRIVAÇÃO DE LIBERDADES: EM BUSCA DO DIREITO AO DESENVOLVIMENTO DA PESSOA COM DEFICIÊNCIA}

pessoa com deficiência no Reino Unido o fez disparar de 23,1\% para 47,4\%, demonstrando a importância de analisar esse grupo social de maneira mais específica. (VITAL, 2008).

No Brasil, conforme os resultados apresentados pelo Censo Demográfico de 2010, realizado pelo Instituto Brasileiro de Geografia e Estatística - IBGE tem-se o número de 45 milhões de pessoas com pelo menos uma deficiência, correspondendo, assim, a 23,9\% da população brasileira, mostrando-se bastante expressivo o contingente de indivíduos que contemplam este grupo de vulneráveis.

No que toca à privação do direito à educação que experimentam as pessoas com deficiência, os dados estatísticos fornecidos, igualmente, pelo Censo de 2010 demonstram que as pessoas com deficiência apresentam uma taxa de alfabetização inferior (81,7\%), quando comparadas com as taxas da população como um todo (90,6\%), de modo que $61 \%$ dos brasileiros que têm deficiência não possuem instrução ou têm apenas o ensino fundamental incompleto, tendo tão somente 7\% dessas pessoas o ensino de nível superior.

Quanto à variável empregabilidade, segundo os dados da Relação Anual de Informações Sociais - RAIS de 2015, divulgada pelo Ministério do Trabalho, apenas 403 mil pessoas com deficiência atuam formalmente no mercado de trabalho, correspondendo a um percentual de $0,84 \%$ do total dos vínculos empregatícios.

Destarte, em que pese estar a nação brasileira em franco progresso econômico, no que diz respeito ao desenvolvimento humano, apresenta-se como um país em destacado declínio; prova disto é o baixo número de pessoas com deficiência em setores básicos que efetivamente promovem a tão sonhada inclusão, notadamente o da educação e do trabalho.

A ausência, sobretudo, de oportunidades educacionais e laborais e, por conseguinte, financeiras, é incisiva para engendrar a restrição das potencialidades das pessoas com deficiência, que, privadas de suas liberdades, facilmente caem na armadilha da pobreza, a qual age de forma mais perversa e cruel sobre elas.

Assim, resultando a deficiência da interação entre as pessoas com deficiência com as barreiras econômicas, sociais e políticas, as quais, sediadas no preconceito e na ignorância, engendram a estagnação social e o estigma da pobreza neste grupo de minorias, a identificação e consequentemente remoção de tais impedimentos, combinadas com mudanças culturais, legislativas, políticas, institucionais e ambientais, são medidas urgentes que se impõem.

Portanto, não se faz prescindível que os governos e toda a sociedade assegurem às pessoas com deficiência, em igualdade de condições com as demais pessoas sem deficiência, o acesso às prestações necessárias à garantia das condições mínimas para uma vida com 
dignidade, sob pena de a possibilidade de sobrevivência humana se figurar obstada, pelo sintoma da pobreza e, assim, desaparecer qualquer estado de liberdade do indivíduo.

\section{CONSIDERAÇÕES FINAIS}

A despeito de ter o conceito de desenvolvimento ultrapassado variáveis tradicionais relacionadas ao crescimento puramente econômico, para se fixar nos Direitos Humanos e, segundo a Teoria Seniana, na ampliação das liberdades, as pessoas com deficiência continuam a experimentar diversas desvantagens associadas às suas limitações funcionais, assim como ocorria no modelo médico.

Mesmo diante de uma deficiência radicada no modelo social, que enfoca tal condição nas barreiras sociais, culturais, políticas e econômicas, e tendo sido este novo paradigma ratificado pela Convenção da ONU sobre os Direitos da Pessoa com Deficiência - CDPD, que tratou do tema sob o viés da dignidade humana, as pessoas com deficiência não gozam de uma vida independente e se veem obstadas de participar ativa e integralmente da comunidade.

Com efeito, da ausência de autonomia e de participação pública e social, decorre o óbice aos direitos essenciais e a uma mínima condição de vida, notadamente educação e empregabilidade, aliado à privação das pessoas com deficiência de oportunidades determinantes para um desenvolvimento com liberdade.

Neste contexto, a maioria das pesquisas relacionadas às pessoas com deficiência aponta que estes apresentam os menores índices de emprego e de formação educacional quando comparados à população em geral, redundando, assim, em taxas acentuadas no que tange à pobreza.

Por outro lado, sem alcance dos serviços de saúde, a pobreza termina por ensejar a deficiência, em virtude da destruição ou do fortalecimento de doenças já existentes nos indivíduos vulneráveis, além de evidenciar, desta maneira, que a deficiência, além de causa, é também consequência da pobreza.

Assim, é necessário retirar as pessoas com deficiência da invisibilidade e do isolamento que as impedem de ampliar suas capacidades e de ter acesso às regulares oportunidades sociais, culturais e políticas. E, para tanto, deve-se priorizar as pessoas com deficiência, por meio da identificação e eliminação de barreiras que assolam este grupo, com a criação e implementação de políticas públicas, que, combinadas com mudanças sociais, legislativas, culturais, promovam o verdadeiro desenvolvimento humano deste expressivo contingente. 


\section{REFERÊNCIAS}

BANCO MUNDIAL. Relatório sobre o desenvolvimento mundial. Washington: Banco Mundial, 2006. Disponível em: $<$ http://siteresources.worldbank.org/INTWDR2006/Resources/4773831127230817535/0821364154.pdf>. Acesso em: 17 out.2017.

COUTINHO, D. R. Direito, desigualdade e desenvolvimento. São Paulo: Saraiva, 2013. COULANGES, F de. A cidade Antiga. São Paulo: Martin Claret, 2013.

DINIZ, D. Modelo social da deficiência: a crítica feminista. Série Anis, Brasília, v. 28, p. 110, 2003. Disponível em:

$<$ http://www.anis.org.br/serie/artigos/sa28(diniz)deficienciafeminismo.pdf>. Acesso em: 17 out. 2017.

FERRAZ, C. V.; LEITE, G. S. A proteção jurídica da pessoa com deficiência como uma questão de Direitos Humanos. In: FERRAZ, C. V.; LEITE, G. S. (Org.). Direito à Diversidade. São Paulo: Atlas, 2015.

FRANÇA, T.; RIOS NETO, E. A escolarização das pessoas com deficiência no Brasil: atendimento, atraso e progressão no Ensino fundamental segundo o Censo 2000. Revista Brasileira de Estudos de População, 2012.

FURTADO, C. Desenvolvimento e subdesenvolvimento. Rio de Janeiro: Fundo de Cultura, 1961.

KUZNETS, S. Economic growth and income inequality. American Economic Review, v. 45, 1955.

National income. Encyclopaedia of the Social Sciences, v. XI, 1933. Disponível em: http://www.nber.org/chapters/c2258.pdf. Acesso em: 25 out. 2017.

LAFER, C. A reconstrução dos Direitos Humanos: um diálogo com o pensamento de Hannah Arendt. São Paulo: Companhia das Letras, 1988.

MARX, K. Contribuição à crítica da economia política. Tradução Florestan Fernandes. São Paulo: Flama, 1946.

MITRA, S.; POSARAC, A.; VICK, B. Disability and Poverty in Developing Countries: A snapshot from the world health Surrey. Social Protection Discussion, ${ }^{\circ} 1109$. World Bank, 2011.

OLIVER, M. The individual and social models of disability. Paper presented at Joint Workshop of the Living Options Group and the Research Unit of the Royal College of 
Physicians, 23 jul. 1990. Disponível em: <http://www.leeds.ac.uk/disabilitystudies/archiveuk/Oliver/in\%20 soc\%20 dis.pdf/>. Acesso em: 10 out. 2017.

Organização Mundial da Saúde. Relatório Mundial sobre a Deficiência. São Paulo: SEDPcD, 2012. Disponível em: <http://www.afro.who.int/sites/default/files/201706/9788564047020.pdf > . Acesso em: 22 nov. 2017.

PALACIOS, A.; BARIFFI, F. La discapacidad como una cuestión de derechos humanos una aproximación a la Convención Internacional sobre los Derechos de las Personas con Discapacidad. Madri: Ediciones Cinca, 2007.

PINHEIRO, M. M. S. As liberdades humanas como bases do desenvolvimento: uma análise conceitual da abordagem das capacidades humanas de Amartya Sen. Rio de Janeiro: IPEA, 2012. Disponível em: <https://www.unric.org/pt/pessoas-com-deficiencia/5459>. Acesso em: 10 out. 2017.

RICARDO, D. Princípios de economia política e tributação. Tradução Paulo Henrique Ribeiro Sandroni. São Paulo: Nova Cultura, 1996.

SACHS, I. Repensando o crescimento econômico e o progresso social: o âmbito da política. In: ARBIX, G.; ZILBOVICIUS, M.; ABRAMOVAY, R. (ORG.). Razões e ficções do desenvolvimento. São Paulo: Editora Unesp; Edusp, 2001. 2008.

Desenvolvimento Includente, Sustentável, Sustentado. Rio de Janeiro: Garamond, SANTOS, B. de S. Para uma revolução democrática da justiça. 3 ed. rev. e aum. São Paulo: Cortez, 2011.

SEN, A. K. Desenvolvimento como liberdade. São Paulo: Companhia das Letras, 2010.

SENGUPTA, A. On the teory and practice of right to development. In: SENGUPTA, A.; NEGI, A.; BASU, M. (Eds.). Reflections on the right to development. Nova Delhi: Centre for Development and Human Rights, Sage Publications, 2005.

SMITH, A. A riqueza das nações: investigação sobre a sua natureza e as suas causas. Tradução Luiz João Baraúna. São Paulo: Nova Cultura, 1996.

UGÁ. V. D. A categoria “pobreza” nas formulações de política social do Banco Mundial. Revista de Sociologia e Política, Curitiba, UFPR, n. 23, p. 55-62, nov. 2004.

VEIGA, J. E da. Desenvolvimento sustentável: o desafio do século XXI. Rio de Janeiro: Garamond, 2005.

. Neodesenvolvimentismo: quinze anos de gestação. São Paulo em Perspectiva, São Paulo, Fundação Seade, v. 20, n. 3, p. 83-94, jul./set. 2006. Disponível em: $<$ http://produtos.seade.gov.br/produtos/spp/v20n03/v20n03_07.pdf>. Acesso em 11 nov. 2017. 
WORLD BANK. 2000-2001. World Development Report. Attacking Poverty. Washington, D. C.: The World Bank Group.

VITAL, F.M. Preâmbulo. In: RESENDE, A.P.C.; VITAL, F.M. de P. (Org.). A convenção sobre os direitos das pessoas com deficiência. Brasília: CORDE, 2008.

WERNECK, C. Ninguém mais vai ser bonzinho na sociedade inclusiva. Rio de janeiro. WVA, 2000. 